\title{
Call for papers: The food environment in Canada
}

Tweet this Call for Papers

Health Promotion and Chronic Disease Prevention in Canada: Research, Policy and Practice

Special Issue on: The Food Environment in Canada

Editors: Robert Geneau (Editor-in-Chief, Public Health Agency of Canada) and Lana Vanderlee (guest editor; Department of Nutritional Sciences, University of Toronto)

Diet is a fundamental component of health, and dietary habits are closely linked with the development of chronic disease and obesity. The food environment in which people make their food choices plays a major role in establishing eating habits and overall diet quality. Broadly defined as the physical, economic, policy and socio-cultural surroundings, opportunities and conditions that influence food choices and nutrition status, the food environment can promote or impede healthy diets.

The current food environment in Canada does not consistently support healthy food choices, which is reflected in the overall poor dietary habits of Canadians. Nationally and internationally, greater attention is being paid to how the food environment can be shifted towards one that is conducive to healthier food patterns.

Health Promotion and Chronic Disease Prevention in Canada: Research, Policy and Practice is seeking articles that examine the food environment in Canada. All article types are invited for submission. We are seeking research relating to all aspects of food environment, which may include, but is not limited to, food composition, labelling, promotion and marketing, provision and procurement, retail, prices, and trade and investment. In particular, we are seeking articles that:

- Characterize the current Canadian food environment

- Examine the impact of food environment policies and interventions in the Canadian context

- Synthesize evidence regarding the state of the food environment in Canada

Kindly submit articles to Journal_HPCDP-Revue_PSPMC@phac-aspc.gc.ca by October 31, 2016. Submissions should mention this Call for Papers

For more information on submission guidelines and article types, visit http://www.phac-aspc.gc.ca/publicat/hpcdp-pspmc/ authinfo-eng.php 